\section{CIVILISATION AND EVESIGHT}

$\mathrm{T}$ his interesting paper on "The Influence of Civilisa1 tion upon Eyesight," read recently before the Society of Arts, Mr. Brudenell Carter supports the commonly received view that the vision of savages is far more acute than that of civilised men. In some sense this is doubtless true; but that the cyes of savages, considered merely as optical instruments, are greatly superior to our own appears to be inconsistent with optical laws and facts long since established by the labours of Airy, Helmholtz, and other investigators. It is known to physicists that the resolving power of an optical instrument is limited by its aperture. With a given aperture no perfection of execution will carry the power to resolve double stars, or stripes alternately dark and bright, beyond a certain point, calculable by the laws of optics from the wave-length of light. With sufficient approximation we may say that a double star cannot be fairly resolved unless its components subtend an angle exceeding that subtended by the wave-length of light at a distance equal to the aperture. If we take the aperture of the eye as $1 \cdot 5^{\text {th }}$ inch, and the wave-length of light as $\mathrm{I}-40$,oooth inch, this angle is found to be about 2 minutes ; and we are forced to the conclusion that there is no room for the eye of the savage to be much superior in resolving power to those of civilised physicists, whose powers approach at no great distance the theoretical limit as determined by the aperture.

It has always appeared to me that the superiority of the savage is a question of attention and practice in the interpretation of minute indications, and that it is comparable with the acuteness of the blind in drawing conclusions from slender acoustical premises. It would be an interesting stibject for investigation, but I should not expect to find that when put to a direct test blind people were able to hear sounds wholly inaudible to others.

The increasing prevalence of short sight is a very important matter, worthy of all attention. There is one fact in connection with it which I avail myself of this opportunity of mentioning, in the hope of inducing scientific oculists to give it further examination. I find that, though not at all short-sighted under ordinary circumstances, I become decidedly so in a nearly dark room, seeing much better with spectacles of 36 inches negative focus. In a moderately good light I see rather better without the glasses than with them. From the few observations that I have made I have reason to believe that this peculiarity of vision is not uncommon. With the aid of a set of concave glasses it is easy to try the experiment in a room lighted with gas. The flame should be gradually turned lower ard lower, so as to give full time for the pupil to dilate, and for the eye to acquire its maximum sensitiveness. In my own case the most marked indication of better definition is the augmentation of binocular relief.

RAYLEIGH

\section{THE INTERNATIONAL INVENTIONS} EXHIBITION

\section{$\mathrm{T}^{\mathrm{H}}$}

HERE seems now little reason to doubt of the success of the South Kensington Exhibition of next summersuccess, that is, from an educational and scientific point of view. What its financial result may be depends upon a variety of circumstances, and perhaps, since it is very improbable that there can be any serious deficit, while, if there is a large surplus, its disposal will, as usual, form a problem difficult of solution, this part of the question does not really very much matter. That Londoners will have a pleasant outdoor lounging place, that there will be abundance of music, that the fountains will be as pretty as last year and the gardens prettier, all this may be taken for granted; but there now scems every reasonable expectation that we shall have more than this, and that the Exhibition will be what it professes to be-a complete illustration of the progress made in the application of science to industry during the past twenty years. At all events if it is not it will be the fault of the promoters, since they have had so large a range of choice that it has only been possible to find space for some third of the applicants, and an enormous number of exhibits have been rejected, not because they were unsuitable or uninteresting, but simply becausc, when there was not room for all, some must of necessity be excluded.

To begin with, it was thought best to exclude, not only the actual articles which were shown last year, but inventions of the same class, and consequently there will be found at South Kensington this year few, if any, exhibits relating to food, clothing, or sanitation. It appears that this rule has given rise to a certain amount of heart-burning, since reference is found to all these heads in the official classification; but it must be remembered that the announcement was duly made at the beginning that the space to be allotted to these and certain other classes would be strictly limited, and then again it was impossible to foresee how large would be the response to the invitations issued. The task of selection has been a difficult, and indeed an invidious, one; but we think it will be found, when the show is opened in May next, that this thankless task has been performed with great judgment, and with a just consideration of the claims of exhibitors on the one hand, and the interest of the public on the other.

We are glad to have heard that in none of the thirtyone groups into which the inventions' half (we are not now considering the musical part) of the Exhibition is divided, have the applications been deficient; in some they are naturally better than others, but in every one there is cnough to provide a fair representation of the condition of its particular industry, and of the improvements which have been made in it during the limits of time with which the Exhibition is concerned. Even this will doubtless be a cause of complaint to those who believe that injury will be done to our manufacturers by the opportunity given to foreigners of imitating our wares and the methods by which they are produced. This is a specious but a somewhat narrow-minded notion; the carly history of invention is full of stories of the efforts of inventors to keep their inventions secret, and the constant failure of such efforts may be taken as one of the principal causes which produced the modern Patent system, under which an inventor is protected, so far as law can protect him, in the enjoyment of the property he has created. There are, of course, many instances of processes worked, and successfully worked, in secret ; but these are the exception, and on the whole it is found that inventors individually, and industry generally, gain far more by a system of publicity than by one of concealment. So it is with exhibitions. It may be taken as tolerably certain that mant1facturers who have any special process which they desire to keep to themselves will not select that particular process for exhibition, and that on the whole manufacturers find exhibitions profitable or they would not be so anxious to engage in them. The suggestion that was made by some wiseacre that the Exhibition should be confined to untried inventions, so that manufacturers (who of course have no other means of hearing of novelties in their own trades) might have the benefit of seeing them, does not, perhaps, call for serious refutation. If the curious collection of rubbish which fills the big building at Washington, devoted to the United States Patent Office, were carted across the Atlantic, and placed in the Kensington Galleries, it is a question whether the public would be morc bored, or the manufacturers less instructed.

As would naturally be expected, in an exhibition of this character, machinery will occupy a tar larger proportion of the space than on previous occasions; we understand that it has therefore been necessary to make considerable additions to the motive power provided for the 